\title{
Evaluating context-specific evidence-based quality improvement intervention on lymphatic filariasis mass drug administration in Northern Ghana using the RE-AIM framework
}

\author{
Alfred Manyeh ( $\nabla$ alfredmanyeh4u@gmail.com ) \\ Dodowa Health Research Centre https://orcid.org/0000-0002-7005-5707 \\ Tobias Tobias \\ University of the Witwatersrand Faculty of Health Sciences \\ Rohit Ramaswamy \\ University of North Carolina at Chapel Hill Gillings School of Global Public Health \\ Frank Baiden \\ London School of Hygiene and Tropical Medicine \\ Latifat Ibisomi \\ University of the Witwatersrand Faculty of Health Sciences
}

\section{Research}

Keywords: Lymphatic Filariasis, Quality Improvement, Mass Drug Administration, RE-AIM, Northern Ghana

Posted Date: June 12th, 2020

DOI: https://doi.org/10.21203/rs.3.rs-34606/v1

License: (c) (i) This work is licensed under a Creative Commons Attribution 4.0 International License. Read Full License 


\section{Abstract}

Background

Over a decade of implementing a global strategy to eliminate lymphatic filariasis in Ghana through mass drug administration, the disease is still being transmitted in 22 districts out of an initial 98 endemic districts identified in 2000. A context-specific evidence-based quality improvement intervention was implemented in the Bole District of Northern Ghana after an initial needs assessment. This study aimed to evaluate the process and impact of the intervention on implementation of lymphatic filariasis mass drug administration in Bole District of Northern Ghana.

Method

The study used the RE-AIM (Reach, Effectiveness, Adoption, Implementation, and Maintenance) framework based on a mixed-methods approach to evaluate the context-specific evidence-based quality improvement intervention.

Results

The findings of the evaluation showed that there was an improvement in social mobilization and sensitization, knowledge about LF and MDA process, willingness to ingest the medication, and adherence to the DOT Strategy. We observed a $6.3 \%$ increase in the district MDA coverage and reduction in self-reported adverse drug reaction. The level of reach, effectiveness and adoption as the district, sub-district and at the individual participants' level suggest that the CEQI intervention is feasible to implement in LF hotspot districts based on initial context-specific needs assessment.

Conclusion

The study provided the groundwork for future application of the RE-AIM framework to evaluate the implementation of context-specific evidence-based quality improvement intervention to improve LF MDAs towards the elimination of LF as a public health problem.

\section{Background}

\section{Lymphatic filariasis mass drug administration}

Lymphatic filariasis (LF) commonly known as elephantiasis is a mosquito-borne incapacitating and disfiguring disease caused by three species of parasitic worms (Wuchereria bancrofti, Brugia malayi, and B. timori). LF is rarely fatal, but at the clinical stage, it causes lymphedema, elephantiasis, and hydrocele. These conditions cause severe pain and result in permanent disability, social exclusion and loss of productivity [1]. LF has been endemic in Africa, Asia, the Pacific, and the Americas historically [2]. Approximately one billion people from 72 countries were at-risk for LF infection, with nearly 36 million people being affected by LF associated morbidity before the World Health Organization (WHO) established the Global Program to Eliminate Lymphatic Filariasis (GPELF) in 2000 [3]. The goal of the GPELF is to eliminate LF in all disease-endemic areas by 2020.

The main approach recommended by GPELF was based on reduction of microfilaria $(\mathrm{mf})$ prevalence in endemic communities below $<1 \%$ through mass drug administration (MDA) of anti-filarial medicine. The recommended antifilarial medicine for sub-Saharan Africa is either diethylcarbamazine or ivermectin and albendazole. This strategy is recommended to be implemented for at least five years with effective population treatment coverage of $\geq 65 \%$. This 
is because the life expectancy of an adult worm is from 4 to 6 years. It is therefore expected that the disease transmission should be interrupted after five years of effective treatment coverage.

The main GPELF strategy to interrupt transmission is MDA using combinations of two antifilarial medicines (albendazole plus either diethylcarbamazine or ivermectin) delivered once yearly to entire eligible populations in endemic areas. The recommended regimen in sub-Saharan Africa is either diethylcarbamazine or ivermectin and albendazole for a minimum of 5 years with effective population treatment coverage $(\geq 65 \%)$.

Ghana became one of the first West African countries to implement MDA intervention through the Ghana Filariasis Elimination Program (GFEP). The implementation of this evidence-based intervention started in 10 endemic districts in 2001 and reached national coverage by 2006.

The GFEP aims to reduce LF prevalence level to below $1 \%$ after $4-6$ rounds of high-coverage $(>80 \%)$ MDA $[4,5]$.

r Over a decade of implementing the MDA intervention in Ghana, the transmission of the disease persists in 22 districts out of an initial 98 endemic districts [6]. These 22 districts have microfilariae prevalence rate above the $1 \%$ threshold, there is a need for interruption of the disease transmission and are now termed LF "hotspot" districts [6]. Bole District in Northern Ghana is one of the districts with the highest microfilariae prevalence in Ghana [5]. In 2016, microfilariae prevalence in Bole District was $1.9 \%$ with some communities having a prevalence rate as high as $5.9 \%$ [5].

\section{The context-specific evidence-based quality improvement intervention}

In 2017, TDR, the Special Program for Research and Training in Tropical Diseases funded a project to conduct implementation research (IR) towards the elimination of LF in Bole District of Northern Ghana. An initial needs assessment to identify implementation bottlenecks associated with the LF MDA intervention in the Bole District of Ghana was conducted using a mixed-methods approach. This strategy was used to gain a deeper understanding of the critical issues affecting the implementation of the LF MDA from the perspective of the services providers (health workers) and frontline workers (community drug distributors), stakeholders (community leaders) and the clients (community members) [5]. The framework connecting all three (3) phases of the study is detailed in Fig. 1.

The results of the pre-intervention phase indicated that the continuous transmission of LF in the Bole District is characterized by refusal to take the drug due to poor knowledge and misconceptions of the disease, poor community mobilization and sensitization, the fear of adverse drug reactions, non-adherence to the directly observed treatment strategy, poor adherence to the MDA protocol and non-participants' responsiveness as detailed elsewhere [5].

Based on the findings of the pre-intervention phase, a context-specific evidence-based quality improvement (CEQI) intervention was designed and implemented using Intervention Mapping (IM), and Plan-Do-Study-Act (PDSA) approaches [5]. The CEQI intervention was based on four (4) key strategies namely: training of community drug distributors (CDDs), social mobilization and sensitization, the involvement of community leaders and other stakeholders and improving the drug distribution process. Each of these strategies was described in terms of seven (7) domains: actor, the action, action targets, temporality, dose, implementation outcomes addressed, and theoretical justification as shown in Table 1 [5].

As part of the monitoring process and to ensure successful implementation and sustainability of the CEQI, a CEQI implementation team with representation from the district and the sub-districts was formed. The key obligation of 
the implementation team was to ensure the smooth implementation and sustainability of the CEQI intervention.

Besides, a WhatsApp group was created to link members of the implementation team. The group platform facilitates the sharing of ideas and resolving of challenges faced during the implementation of the CEQI intervention as shown elsewhere [5]. The WhatsApp platform was also used by the principal investigator (the first author) to review work progress and reinforce compliance with the components of the CEQI. 
Table 1

Description of components of the context-specific evidence-based quality improvement intervention

\begin{tabular}{|c|c|c|c|c|}
\hline Domain & $\begin{array}{l}\text { Strategy: Training of } \\
\text { Community Drug } \\
\text { Distributors (CDDs) }\end{array}$ & $\begin{array}{l}\text { Strategy: Social } \\
\text { Mobilization and } \\
\text { Sensitization }\end{array}$ & $\begin{array}{l}\text { Strategy: Involvement } \\
\text { of Community Leaders } \\
\text { and other } \\
\text { Stakeholders }\end{array}$ & $\begin{array}{l}\text { Strategy: Drug } \\
\text { Distribution } \\
\text { Process }\end{array}$ \\
\hline Actor(s) & $\begin{array}{l}\text { - District Director, Sub- } \\
\text { district NTD focal } \\
\text { persons, disease } \\
\text { control officers and } \\
\text { implementation/QI } \\
\text { team (District and } \\
\text { sub-district NTDs } \\
\text { focal persons and } \\
\text { heads, DCO, HPO, } \\
\text { Assemblymen/women } \\
\text { and PI) who have } \\
\text { been trained. }\end{array}$ & $\begin{array}{l}\text { - Intervention } \\
\text { implementation/QI } \\
\text { team (District and } \\
\text { sub-district NTDs } \\
\text { focal persons, } \\
\text { opinion, religious } \\
\text { and traditional } \\
\text { leaders and PI). }\end{array}$ & $\begin{array}{l}\text { - Intervention } \\
\text { implementation/QI } \\
\text { team. }\end{array}$ & $\begin{array}{l}\text { - Intervention } \\
\text { implementation/Q। } \\
\text { team and CDDs }\end{array}$ \\
\hline
\end{tabular}




\begin{tabular}{|c|c|c|c|c|}
\hline Domain & $\begin{array}{l}\text { Strategy: Training of } \\
\text { Community Drug } \\
\text { Distributors (CDDs) }\end{array}$ & $\begin{array}{l}\text { Strategy: Social } \\
\text { Mobilization and } \\
\text { Sensitization }\end{array}$ & $\begin{array}{l}\text { Strategy: Involvement } \\
\text { of Community Leaders } \\
\text { and other } \\
\text { Stakeholders }\end{array}$ & $\begin{array}{l}\text { Strategy: Drug } \\
\text { Distribution } \\
\text { Process }\end{array}$ \\
\hline Action(s) & $\begin{array}{l}\text { - Train drug } \\
\text { distributors to have a } \\
\text { good understanding } \\
\text { of the programme and } \\
\text { to be able to instil the } \\
\text { same knowledge to } \\
\text { the community } \\
\text { members. } \\
\text { - Train drug } \\
\text { distributors to be able } \\
\text { to convince every } \\
\text { qualified person in the } \\
\text { endemic area to } \\
\text { participate in the MDA } \\
\text { exercise. } \\
\text { - Train drug } \\
\text { distributors on the } \\
\text { inclusion and } \\
\text { exclusion criteria of } \\
\text { the MDA. } \\
\text { - Train drug } \\
\text { distributors on the } \\
\text { possible adverse drug } \\
\text { reactions and be able } \\
\text { to explain them to the } \\
\text { community members. } \\
\text { - Instilling the skills of } \\
\text { communication and } \\
\text { interaction to the drug } \\
\text { distributors and the } \\
\text { importance of being } \\
\text { patient and tolerant } \\
\text { with difficult } \\
\text { community members. } \\
\text { - Vigorous } \\
\text { enforcement of the } \\
\text { MDA procedures, in } \\
\text { particular, DOT policy } \\
\text { during training and } \\
\text { supervision. }\end{array}$ & $\begin{array}{l}\text { - An evidence- } \\
\text { based, multi- } \\
\text { channel } \\
\text { communication } \\
\text { strategy to result } \\
\text { in high levels of } \\
\text { awareness among } \\
\text { community } \\
\text { members, (radio } \\
\text { discussions and } \\
\text { announcements, } \\
\text { announcements in } \\
\text { churches, } \\
\text { mosques, schools, } \\
\text { etc., community } \\
\text { durbars and } \\
\text { meetings with } \\
\text { social groups to } \\
\text { explain MDA } \\
\text { relevance and } \\
\text { public/community } \\
\text { announcements). } \\
\text { - Focus key } \\
\text { messages on } \\
\text { cause and mode } \\
\text { of transmission of } \\
\text { the disease, } \\
\text { importance of the } \\
\text { MDA and how to } \\
\text { identify, what to } \\
\text { do and minimize } \\
\text { adverse drug } \\
\text { reactions. }\end{array}$ & $\begin{array}{l}\text { - Community/Opinion } \\
\text { leaders such as Chiefs, } \\
\text { Assemblymen/women, } \\
\text { religious and } \\
\text { traditional leaders } \\
\text { should be involved in } \\
\text { the MDA exercise. }\end{array}$ & $\begin{array}{l}\text { - An adequate } \\
\text { number of days } \\
\text { should be } \\
\text { dedicated to the } \\
\text { distribution } \\
\text { exercise (not less } \\
\text { than } 1 \text { week) } \\
\text { - The distribution } \\
\text { should reach } \\
\text { people in } \\
\text { institutions, } \\
\text { markets, places, } \\
\text { offices and } \\
\text { homes. } \\
\text { - People with } \\
\text { higher-level } \\
\text { qualifications and } \\
\text { a good knowledge } \\
\text { of the MDA should } \\
\text { be sent to } \\
\text { institutions and } \\
\text { offices to } \\
\text { distribute the drug. } \\
\text { - Strong } \\
\text { enforcement of } \\
\text { the DOT policy. }\end{array}$ \\
\hline $\begin{array}{l}\text { Target (s) of } \\
\text { the action }\end{array}$ & $\begin{array}{l}\text { - Drug distributors in } \\
\text { the endemic } \\
\text { communities. }\end{array}$ & $\begin{array}{l}\text { - People in the } \\
\text { endemic } \\
\text { communities. }\end{array}$ & • Community leaders. & $\begin{array}{l}\text { - People in the } \\
\text { endemic } \\
\text { communities. }\end{array}$ \\
\hline Temporality & $\begin{array}{l}\text { - The drug distribution } \\
\text { should start within } \\
\text { one week after the } \\
\text { training of drug } \\
\text { distributors. }\end{array}$ & $\begin{array}{l}\text { - Social } \\
\text { mobilization and } \\
\text { sensitization } \\
\text { should start two } \\
\text { weeks before and } \\
\text { should continue } \\
\text { during the MDA. }\end{array}$ & $\begin{array}{l}\text { - Before, during and } \\
\text { after MDA exercise. }\end{array}$ & $\begin{array}{l}\text { - During the drug } \\
\text { distribution }\end{array}$ \\
\hline
\end{tabular}

Note CDD: Community Drug Distributors, DCO: Disease Control Officer, HPO: Health Promotion Officer, QI: Quality Improvement, DOT: Direct Observed Treatment MDA: Mass Drug Administration [5]. 


\begin{tabular}{|c|c|c|c|c|}
\hline Domain & $\begin{array}{l}\text { Strategy: Training of } \\
\text { Community Drug } \\
\text { Distributors (CDDs) }\end{array}$ & $\begin{array}{l}\text { Strategy: Social } \\
\text { Mobilization and } \\
\text { Sensitization }\end{array}$ & $\begin{array}{l}\text { Strategy: Involvement } \\
\text { of Community Leaders } \\
\text { and other } \\
\text { Stakeholders }\end{array}$ & $\begin{array}{l}\text { Strategy: Drug } \\
\text { Distribution } \\
\text { Process }\end{array}$ \\
\hline Dose & $\begin{array}{l}\text { - The training of the } \\
\text { CCDs should be } \\
\text { detailed enough to } \\
\text { equip them well for } \\
\text { the MDA task, and the } \\
\text { training period should } \\
\text { not be more than one } \\
\text { day to enhance their } \\
\text { active participation in } \\
\text { the training. }\end{array}$ & $\begin{array}{l}\text { - Each endemic } \\
\text { community should } \\
\text { have at least two } \\
\text { social } \\
\text { mobilization and } \\
\text { sensitization } \\
\text { exercises } \\
\text { (community } \\
\text { durbar, school } \\
\text { education, } \\
\text { information centre } \\
\text { announcement, } \\
\text { education at } \\
\text { church and } \\
\text { mosque, and or } \\
\text { radio talk shows } \\
\text { etc.) for the start } \\
\text { of MDA and at } \\
\text { least one during } \\
\text { MDA. }\end{array}$ & $\begin{array}{l}\text { - Every endemic } \\
\text { community must have } \\
\text { a community leader } \\
\text { representing it. }\end{array}$ & $\begin{array}{l}\text { - The distribution } \\
\text { exercise should } \\
\text { not be less than } 1 \\
\text { week in the } \\
\text { endemic district. } \\
\text { - Over } 80 \% \text { of the } \\
\text { people in the } \\
\text { endemic } \\
\text { communities must } \\
\text { be covered. }\end{array}$ \\
\hline $\begin{array}{l}\text { Implementation } \\
\text { outcome (s) } \\
\text { and effect }\end{array}$ & $\begin{array}{l}\text { - Increase the level of } \\
\text { adherence to LF MDA } \\
\text { implementation } \\
\text { procedures and } \\
\text { participants' } \\
\text { responsiveness. }\end{array}$ & $\begin{array}{l}\text { - At least 15\% } \\
\text { increase in MDA } \\
\text { coverage and } \\
\text { reduction in the } \\
\text { number of } \\
\text { refusals } \\
\text { (increased } \\
\text { participant } \\
\text { responsiveness). }\end{array}$ & $\begin{array}{l}\text { - At least } 15 \% \text { increase } \\
\text { in MDA coverage and } \\
\text { reduction in the } \\
\text { number of refusals } \\
\text { (increased participant } \\
\text { responsiveness). }\end{array}$ & $\begin{array}{l}\text { - At least } 15 \% \\
\text { increase in MDA } \\
\text { coverage and } \\
\text { reduction in the } \\
\text { number of } \\
\text { refusals } \\
\text { (increased } \\
\text { participant } \\
\text { responsiveness). }\end{array}$ \\
\hline Justification & $\begin{array}{l}\text { - Researchers suggest } \\
\text { that drug distributors } \\
\text { are the interface } \\
\text { between MDA } \\
\text { programs and their } \\
\text { targeted population; } \\
\text { hence their adequate } \\
\text { training is crucial to } \\
\text { the success of the } \\
\text { MDA [7-10]. }\end{array}$ & $\begin{array}{l}\text { - It has been } \\
\text { shown that } \\
\text { evidence-based, } \\
\text { context-specific } \\
\text { and multi-channel } \\
\text { social } \\
\text { mobilization and } \\
\text { sensitization is } \\
\text { required for the LF } \\
\text { elimination } \\
\text { program to } \\
\text { succeed }[4,10,11] \text {. }\end{array}$ & $\begin{array}{l}\text { - Stakeholder } \\
\text { engagement and } \\
\text { involvement in LF } \\
\text { MDA cannot be } \\
\text { overemphasized [4, 9, } \\
\text { 10]. }\end{array}$ & $\begin{array}{l}\text { - The MDA } \\
\text { implementation } \\
\text { process is crucial } \\
\text { for participants' } \\
\text { responsiveness to } \\
\text { the program [4, } \\
\text { 10]. }\end{array}$ \\
\hline
\end{tabular}

Reach, Effectiveness, Adoption, Implementation, Maintenance (RE-AIM) framework was used to guide the evaluation of the CEQI intervention implementation. The RE-AIM framework was developed to assess the effects of public health interventions [12]. 
Reach is defined as the proportion of eligible individuals in the aimed population who partook in an intervention program and the extent to which those individuals represent the target population. Effectiveness is the degree to which the intervention program has a positive effect on an outcome(s) of interest. Adoption is a measure of the total number of program providers who implement an intervention and the extent to which they represent all potential program providers. Implementation is an organizational measure of the quality of the intervention's delivery and its adherence to the essential elements of the research program. Implementation is sometimes referred to as treatment fidelity. Maintenance is the measure of the program's effectiveness in attaining the expected outcome for an extended time. It is also a measure of the sustainability of the intervention and indicates whether the intervention is likely to become an institutional culture $[12,13]$.

The RE-AIM has been useful in evaluating intervention in diverse fields including behavioural change interventions $[14,15]$, weight loss studies [16, 17], nutrition projects [18], studies on injury prevention $[19,20]$ and studies on manual activity $[18,21]$. The RE-AIM framework has been applied to assess the effectiveness of a single intervention at employee, community, and patient levels [22]. The framework has also been useful in studying the impact of evidence-based interventions with fidelity and interventions that focus on improving organizational culture and adherence to clinical guideline [23]. It has also been used to assess the impact of single intervention within a context of a broader project [24] and recently to evaluate larger multidimensional interventions [13].

Qualitative, quantitative and the mixed-methods approach to the application of the RE-AIM framework has been demonstrated in evaluating interventions [25]. With awareness of these various options of application of the RE-AIM framework, the primary purpose of this paper is to use the RE-AIM framework to evaluate the effect of CEQI intervention on implementation of LF MDA in the Bole District of Northern Ghana.

\section{Methods}

\section{Study design and data source}

We used mixed-methods study design which involves the extraction of quantitative secondary MDA data from the neglected tropical diseases database in Bole District Health Administration in Northern Region of Ghana. The quantitative data include information on pre and post CEQI intervention MDA coverage and self-reported adverse drug reaction. We also extracted information from weekly written reports submitted by sub-districts heads of health services during the implementation of the CEQI.

The qualitative data was collected from purposively selected participants through in-depth interviews (IDIs) using semi-structured interview guides. The interview guides were pre-tested in a different rural LF endemic district with similar settings as the study district. The IDIs were e conducted with 42 participants, including community leaders, community drug distributors (CDD), and health workers. The health workers include; district and sub-district directors of health services, disease control officers, health information officers, and nurses. The participants for the qualitative arm were purposively selected from six (6) sub-districts to gather enough information for the evaluation of the effect of the intervention. Except for health workers IDIs, all data collection tools were translated into the predominantly spoken local language in the study area.

The data was collected between March - April 2018 by trained graduate research assistants.

All interviews were recorded using digital voice recorders with the consent of the study participants. Detailed field notes and training registers were turned into data documents for analysis. 
The interviews with health workers were conducted in English while that of CDDs and community leaders were held in the local languages and translated into English by two independent language experts during transcription.

\section{Measurements}

\section{Reach}

Reach was assessed at the district, sub-district, CDD, and the individual community member levels.

\section{District level}

Reach was measured as the proportion of the members of the district management team who participated in the training before the 2017 drug distribution.

\section{Sub-district level}

Proportion of sub-district management team who participated in the training of the CDDs' training before 2017 MDA.

Individual community member level

This was assessed using the number of people who received the drug (coverage) during the 2017 MDA.

\section{Effectiveness}

Given the short duration and single implementation cycle of the CEQI intervention, we can do a detailed effectiveness analysis of the intervention at this stage. However, the qualitative method was used to measure the effectiveness of the intervention on the level of knowledge about the LF, understanding of the MDA among the study participants and the involvement of community leaders.

\section{Adoption}

We assessed the level of adoption as the proportion of sub-districts that implemented each component of the CEQI intervention. Through interviews with the study participants, we assessed their level of knowledge to ascertain understanding and information given by the interviewers (CDDs, health workers) on the program. If the interviewers determined that the program was not implemented correctly, they were asked what were the impediments during the implementation and how they planned to overcome them.

\section{Implementation}

The level of implementation was assessed (i.e., fidelity to delivering the CEQI intervention) with the study participants. This was done through the IDIs to explore the level of information they have been given and to determine how well sub-districts adhered to components of strategies during the implementation. We also assessed the activities carried out during the implementation of the CEQI from the weekly report submitted by the sub-districts heads of health services and from the WhatsApp platform.

\section{Maintenance}

Due to the pilot nature of the CEQI intervention, detailed evaluation of maintenance was difficult to assess and to determine the sustainability of the intervention. However, a brief assessment of the district, sub-district and CDD level maintenance of the intervention to determine the extent to which the CEQI intervention can become integrated into the routine activities of the LF MDA. 
We also determined the extent to which the intervention implementation team could continue and sustain the intervention activities. A review of barriers and possible solutions to enable the successful implementation of the intervention from the perspective of the participants (through the IDIs and from weekly written reports) was carried out.

\section{Results}

\section{Reach}

Before the commencement of the 2017 MDA, respondents reported that training, which usually lasts between one and three days, were held for CDDs. According to them, the training focused on teaching CDDs how to administer and handle the MDA drugs, filling the forms. They were also trained on sensitization of community members and to convince individuals who were resistant to take the pills. Respondents also indicated they were taught to identify MDA illegible community members and to ensure all houses are visited during the exercise. The participants reported that training was practical; they were provided with material (books and pictures) of the disease to aid with educating community members, which helped in facilitating their work.

"We were trained for three days, and the training was very good. We were taught a lot about LF and drug distribution. We were also taught how to sensitize our community members to participate in the drug administration" (CDD, Tinga).

\section{District level}

The district director of health service, district disease control officer, district public health officer, and district public health nurse participated in the training sessions. This participation represents $100 \%$ reach for the district level officials who superintends the MDAs in the district.

\section{Sub-district level}

The heads of each of the five (5) sub-districts and their disease control officers participated in the training. Thus 10 (100\%) representation of the sub-districts officials who oversee the implementation of the MDA at the sub-district level. Five (5) nurses from the sub-districts also participated in the training to help with supervision of the CDDs during the MDA.

\section{Community drug distributor level}

A total of 152 CDDs where trained representing $98 \%$ of the total CDDs identified for the MDA in the study district. Three (3) were absent due to ill health, but arrangement was made for them to be trained at the sub-district level before the commencement of the 2017 MDA.

\section{Individual community member level}

A total of 66623 (83.4\%) eligible community members received the LF medication in the study district during the 2017 MDA.

\section{Community leader level}


Two (2) key community leaders from each sub-district (a total of 10) participated in the CDD's training. The community leaders were also involved in the social mobilization and sensitization activities in their various communities in the sub-districts.

\section{Effectiveness}

\section{Knowledge of lymphatic filariasis}

Most of the respondents were able to describe lymphatic filariasis (LF) based on the signs and symptoms exhibited by patients. Others also relied on the causes of the disease in explaining what the disease is. The following are some responses to the question of what LF is:

"...it is a disease that affects the human body and allows some fungi to grow on the affected part, and at a point, you will see the affected area growing to an abnormal position. Sometimes if it is the foot, you will see that foot is extraordinary fatter than the other foot, if it is the hand too, the same thing. But most people I have seen being affected by this disease have it on foot and hardly have I seen somebody being affected by the arm" (Community leader, Mankuma).

"It is a disease that when a mosquito bites a person who is not immunized and comes to bite you, then you also become infected" (CDD, Mandari).

"... it is a disease that affects the lymph system which is mostly caused by mosquito. Mostly when it does happen, it is characterized by swelling, and the body parts it affects are the extremities and the scrotum and other parts of the body" (Health worker, Tinga).

\section{Perception of the respondents on the cause of LF}

Most respondents mentioned being bitten by a mosquito as a cause of the disease. Two respondents (a drug distributor and community leader) however said they had no idea about what causes the disease. There were speculations by one respondent that the disease is caused by witchcraft.

"I don't know what causes the disease, but some said it is caused by witches" (Community leader, Jama).

With regards to preventive methods available for treating LF, most of the respondents indicated that taking the MDA drugs help in preventing the disease.

"... health staffs have made us aware that if you take the drugs consistently, then you can prevent it" (CDD, Jama).

"...the only thing is to be taking the drugs always" (CDD, Mandari).

"... if you know you don't have elephantiasis, and they are sharing the medicine, and you refuse to take them, it can't prevent it unless you have taken the drug" Community leader, Bole).

The study participants were knowledgeable about the signs and symptoms of the disease. The commonest sign mentioned by respondents was swollen limbs or legs. Others were itchiness, rashes, headaches, frequent diarrhoea, dizziness, fever, fear of light, enlargement of the testes, reddish eyes, body pains and weakness in the body.

"...you see one of the legs bigger than the other or very big testicles" (CDD, Jama). 
“...sometimes I see the fellow having reddish eye and itchy body" (Community leader, Mankuma).

\section{Broad understanding of the MDA}

According to respondents, the MDA is the distribution or administration of drugs to all community members (both LF patients and non-patients), to prevent and eradicate lymphatic filariasis. This is usually done using volunteers from the communities with supervision and monitoring from health workers.

"We do the exercise because we don't want anyone to get the disease in addition to those who already have it. It is an attempt to eradicate the disease" (CDD, Bamboi).

"...it has to do with we giving people drugs in our communities so that they are protected from getting the disease... mostly it happens once in a year... we go around to distribute the drugs... mostly we use the volunteers then the health workers do the monitoring and supervision" (Health worker, Tinga).

Although all the respondents agreed that drugs given during the MDA are to prevent LF, some CDDs were also of the view that the drugs are capable of curing blindness and other diseases. It is worth noting that some community members were usually eager to ingest the drug because the drug enhances their sexual performance.

"The medicine makes you active in whatever you are doing. Some community member said they could have sex with their wives and husbands very well" (CDD, Mandari).

\section{Adoption and implementation}

We learnt from the respondents that other activities undertaken before the 2017 MDA included informing the communities about the MDA via a town criers, sensitization in churches, mosques, community information centres and sometimes on local radio stations. On a few occasions, durbars were held to educate community members on the LF disease and the importance of MDA. The endemic communities were also educated on reasons for the MDA and possible side effects of the drugs. Some respondents also reported that they used door to door approach to announce dates and to sensitize households. The reasons given for the announcement by drug distributors were to ensure that people make themselves available on distribution days as most communities' members were farmers who sometimes spent nights on their farms.

"... we pre-inform the people. This is because sometimes, some people go to spend the whole day and nights on the farm. Sometimes we even go to churches to make announcements with regards to the exercise so that the people are overly aware of the exercise" (CDD, Jama).

It is important to note that most drug distributors disclosed that the focus was usually on announcements of dates and not on sensitization. Very few of them mentioned sensitization on the disease, possible side effects and how to handle such as activities they undertook before the commencement of the MDA. Health workers who participated in the study, on the other hand, emphasized community mobilization through durbars and meetings with stakeholders for sensitization as one of the primary activities undertaken before the MDA began. This clearly shows that social mobilization and sensitization before and during the MDA is the responsibility of the health workers. There is an indication that community leaders were involved in the last MDA exercise as shown in the quotes.

"We do what we call social mobilization and we get the stakeholders to involve. We have a meeting with the stakeholders and we discuss what we about to do and we let them know the reason for carrying the exercise because without the stakeholders we can't get the community to participate in the exercise... we have the volunteers

Page 12/24 
involved in the meeting. We orientate them... we then send the information across to enforce the community sensitization after the meeting" (Health worker, Tinga).

"The last time we were informed about the exercise, we beat the 'gong-gong' in the community to inform everyone about the exercise and when it will take place. We then advise them to make sure they avail themselves to take the medication. We also advise and encourage them to stay away from alcohol on the day of the exercise to avoid any complications" (Community leader, Mankuma).

According to the participants, the drug distribution lasted between one and two weeks. Alcoholics, pregnant women, under-heights, lactating mothers, and people who were seriously sick were excluded from the exercise. In cases where household members were unavailable to take the drugs or were unable to ingest the medicine for one reason or the other (sometimes because they were drunk), the house or structure was noted and revisited. Height of household members was measured to determine the dosage of medicine to be given.

"...we have the measuring stick we use to check their height so when we establish that the person can take the drug, we make sure the person takes the drug in our presence... we don't give it to you to take later" (CDD, Tinga).

There is a strong indication that the Directly Observe Treatment (DOT) strategy was adhered to by the CDDs, as indicated in the following quotes:

"...for some of them I fetch water, and they swallow the medicine there... especially those who didn't take for the previous years... so they take it on the spot before I leave the house" (CDD, Tinga).

"...we make sure they take medicine in front of us so that they don't go and throw the drugs away" (CDD, Bole).

The participants revealed that there were several differences which made the most recent exercise more effective compared to previous ones. Some of the differences mentioned include detailed training for CDDs, increase in incentive for CDDs, supportive supervision, assurance of free treatment of adverse drug effects by health service, a higher level of participation and community sensitization.

The respondents indicated that many community members agreed to ingest the medication in the most recent (2017) MDA exercise compared to previous ones. They mentioned that in previous exercises, they had to work hard in convincing community members to ingest the drugs, and it was a different case in the most recent MDA program. We were informed that on some occasions, community members went to the homes of the drug distributors or asked about the drugs even before the commencement of the MDA program. Some drug distributors also mentioned that they faced a minimal challenge in getting community members to comply on distribution day as they were eager and ready to participate in the MDA exercise.

"Formerly they will say they don't know you, but now they say you have not come to my house to give me the medicine" (CDD, Mandari).

"One major improvement is that we were given the assurance that if anyone faces any adverse effect after taking the drugs, they can report at the health facility, and they would be treated for free, and this boosted the confidence of the people in the drugs" (Bole, Tinga).

"Previously, people used to reject the drug and will never take it no matter what you say or do... but during the last distribution, people were in their houses waiting for me to bring the drug" (CDD, Mankuma). 
"As I said earlier, the willingness of community members to ingest the medicine was very high in the last exercise...those who used to complain of drug reactions have now seen the benefits because we always convince them that the drug reactions they experience are because the organisms that cause the disease is already in their body, and so the drug is working on it, and so they need to continue taking the drugs to completely kill the organisms... previously, people used to reject the drug and will never take it no matter what you say or do" (CDD Tinga).

A higher level of compliance in the new exercise, according to some CDDs was due to the claims that the MDA drugs make one more physically active and enhance sexual performance. There was also an indication that community members understood the importance of MDA exercise and so were willing to participate in the activity, which made work easy for CDDs. Pictorial evidence was shown to community members on the signs and symptoms of LF also influenced compliance as it induced some fear and insight about the reality of the disease into community members who were likely to reject the drugs.

"they say when you take it (the medicine), it makes you active in whatever you are doing and some also say they can sleep with their wives and husbands very well" (CDD, Mandari).

"The compliance was better now because they understood the exercise and so they were willing to swallow the drugs... sometimes those who were absent even trace me to come for theirs when they return" (CDD, Bamboi).

"During the previous drug distribution they were not willing to swallow, but last year they were willing due to the photos that we were holding" (CDD, Tinga).

Another difference between the recent MDA and previous ones was the intense training volunteers received before the distribution exercise. Because of this training, respondents reported that they were able to better engage community members and in instances where refusals were imminent, they were able to convince community members to take the drugs.

"...now what we do is that when the fellow wants to refuse to take the drugs, we explain the benefit of the drugs to them. But formerly, if the person doesn't want to take the drug, we leave" (CDD, Mandari).

"...but now because of the intensive training, we take our time to explain to them, so most of them agreed" (CDD, Tinga).

Even though respondents said, they used different channels (religious centres, gong-gong beating, door-to-door approach) to sensitize community members and announce distribution dates, the introduction of some new channels such as the use of community information centres and radios were new additions. These new additions were able to reach a wider population compared with the traditional channel of the house-to-house announcement and gong-gong beating. A CDD had this to say:

"We used to go from house to house to inform people, but now there are information centres around that we were encouraged to use... you can just go there and make the announcements and people hear it from their homes" (CDD, Jama).

Unlike in previous exercises where drugs were just administered without measures in place for treating adverse side effects, respondents felt that provisions that were made in the recent exercise for free treatment of adverse reactions 
helped. Community members were informed on where to seek free health care should they have any adverse drug reaction And that motivated community members to ingest the drugs. As shown in the following quote:

"One other improvement is that we were given the assurance that if anyone faces any adverse effect after taking the drugs, they can report at the health facility, and they would be treated for free, and that boosted the confidence of the people in the drugs" (CDD, Jama).

Respondents also mentioned that an increase in allowances for volunteers and supervision in the most recent exercise compared to previous MDA exercises. These motivated drug distributors to give their best.

"...well, the money we were given in the last MDA exercise was an increment from the previous ones" (CDD, Bamboi).

"In fact, before God and man, there was a slight increment in the allowances that are given to the volunteers in this last MDA exercise, and this encouraged us to work harder" (CDD, Tinga).

"During the last exercise, the MDA officers were around to supervise us, so when you are going astray, they will correct you this helped us a lot" (CDD, Mandari).

Some distributors revealed that coverage in some communities in the recent MDA program was affected by the migration of community members to other parts of the country and so were not accessible. The results also show that the timing of the MDA being Islamic fasting period also contributed to the low participation in some communities.

"I realized that the number of people covered in the previous drug distribution was more than in the recent exercise because many of the people who had written their names in some of the houses were nowhere to be found because most of them had either moved out or travelled" (CDD, Bole).

"...you know Bole is a Muslim community, and the drug was distributed at the time of Ramadan so the people fasting could not take part" (Health Worker, Bole).

The fight against 'galamsey' (Illegal mining of gold) caused a lot of out-migration in some communities hence resulting in several community members not available.

"For my community, the coverage was low because previously, there were a lot of galamsey workers around and so the number of people was very high. But now that the galamsey has been stopped, all those people have moved away, and so it has caused a decrease in the number of people" (CDD, Bole).

"One challenge is that, since this is a galamsey area, you go and register a lot of people, but during the drug distribution they tell you they have moved out" (Health worker, Bole).

There were reports by CDDs that they were unable to complete or cover the areas assigned to them within the stipulated time of the MDA. This was partly because of the increase in compliance or acceptance, which meant more people to attend. Some of the areas within the district had seen some development and population increase. Thus, some households were left out of the exercise.

Other community members rejected MDA drugs due to misconception, fear of side effects and the unwillingness of some health facilities to treat such cases for free. The distance to the nearest health facility to report adverse drug 
reaction was also assigned as reasons for refusal of the drug. CDDs outlined these as challenges encountered during the last MDA exercise.

"Because a lot of people including some visitors were ready to take the drug, I spent more time attending to people in some houses, and I was not able to visit all the houses in my area." (CDD, Mankuma).

"...some of the community people said when they ingest the drug, their legs become swollen and I tell them if it has swollen they should come to the health centre, and they will give them drugs and they said when they go to the health facility, the nurses will not attend to them" (CDD, Tinga).

Some community members refused the drugs because they did not trust the volunteers, accusing volunteers of accepting bribes to administer deadly drugs to them.

"There were even people who would refuse to take the drugs and then ask you to leave their house... they say you have been given money to come and give them drugs for which they may even die after taking" (CDD, Mankuma).

Lack of logistics such as transportation and Protective boots to enable drug distributor access remote areas were among the challenges encountered.

"One thing they can do to help us is provided wellington boots and raincoats for us to be able to reach the communities that have muddy access and when it rains on the way" (CDD, Bamboi).

Community members also had unrealistic demands, demanded incentives such as mosquito nets which were not part of the program.

"Everywhere we go they talk about mosquito nets. They said we always talk about LF and oncho, but we don't give them mosquito nets so they will not take the drugs" (CDD, Tinga).

\section{Maintenance}

Due to the short duration of the CEQI intervention, detailed evaluation of maintenance was difficult to assess and to determine the sustainability of the intervention. However, we reviewed barriers and possible solutions to enable successful implementation and sustainability of the intervention from the perspective of the study participants.

Because of the challenges encountered during the last MDA exercise, respondents suggested that the MDA exercise should be conducted during the dry season when there will be no farming activities as that will ensure accessibility to communities and availability of individual household members. The interval between MDA exercises was reported to be too long, and some CDDs suggested that the interval should be shortened.

"My suggestion is the interval between the MDAs is too long because people continue asking when is the tablet coming" (CDD, Jama).

To ensure the sustainability of the intervention, the CCDs suggested that more knowledgeable people (health worker) should accompany them during to authenticate their credibility during the drug distribution. According to some CDDs, community members knowing volunteers are not medical personnel hence disregard information they give and consider it as inaccurate and incredible.

"We need more help to encourage us to do the job because if it only we the volunteers when we are talking to them, they won't listen to us. They will say you have never been to school, and you are coming to give medicine to us" 
(CDD, Bole).

CDDs also recommended better remuneration, provision of incentives and motivation for community members.

"I think providing us with bicycles and increasing the allowance will help us reach the very far communities easily... and distributing bed-nets to the community members will also help" (CDD, Bamboi).

Some CDDs reported that they were unable to complete or cover the areas assigned to them within the stipulated time of the MDA. This was partly because of the increase in compliance or acceptance, which meant more people to attend. Some of the areas within the district had seen some development and population increase. Thus, some households were left out of the exercise.

Other community members rejected MDA drugs due to misconception, fear of side effects and the unwillingness of some health facilities to treat such cases for free. The distance to the nearest health facility to report adverse drug reaction was also assigned as reasons for refusal of the drug. CDDs outlined these as challenges encountered during the last MDA exercise.

"Because a lot of people including some visitors were ready to take the drug, I spent more time attending to people in some houses, and I was not able to visit all the houses in my area." (CDD, Mankuma).

"...some of the community people said when they ingest the drug, their legs become swollen and I tell them if it has swollen they should come to the health centre, and they will give them drugs and they said when they go to the health facility, the nurses will not attend to them" (CDD, Tinga).

Some community members refused the drugs because they did not trust the volunteers, accusing volunteers of accepting bribes to administer deadly medicines to them.

"There were even people who would refuse to take the drugs and then ask you to leave their house... they say you have been given money to come and give them drugs for which they may even die after taking" (CDD, Mankuma).

Community members also had unrealistic demands, demanded incentives such as mosquito nets which were not part of the program.

"Everywhere we go they talk about mosquito nets. They said we always talk about LF and oncho, but we don't give them mosquito nets so they will not take the drugs" (CDD, Tinga).

One major threat to the sustainability of the CEQI intervention observed is the frequent transfer of health staff within the district. Between 2017 to December 2018, key health worker (senior disease control officers and district director) has been transferred. These health workers were vital members of the CEQI implementation team and management members of the district health administration.

\section{Discussion}

The study aimed to assess the effect of implementing CEQI intervention on implementation of LF MDA in the Bole District of Northern Ghana using RE-AIM. The RE-AIM framework provided a structure to evaluate the impact of the CEQI towards the elimination of the LF as a public health problem in hotspot districts in Ghana.

Page $17 / 24$ 
The findings of the evaluation showed that there was an improvement in social mobilization and sensitization, knowledge about LF and MDA process, willingness to ingest the medication, and adherence to the DOT Strategy. We observed a $6.3 \%$ increase in the district MDA coverage and $0.03 \%$ reduction in self-reported adverse drug reaction.

However, the interventions did not have the desired effects on MDA coverage in Bole sub-district. This was due to the timing of the MDA and peri-urban nature of the sub-district. Bole Sub-district being Muslim dominated population, administering drugs to the people around the Muslim fasting period made it difficult for most people to ingest the medicine, causing the decline in the MDA coverage. Secondly, social mobilization and sensitization strategy, which works well in rural areas did not work in Bole sub-district due to the semi-urban nature of the sub-district.

These observations reveal the contextual complexities of working in semi-urban/urban communities (as demonstrated in Bole sub-district), and that health workers at the local level understand their system and difficulties on the ground much better than the national level team.

The evaluation revealed a substantial improvement in knowledge, risk perceptions and understanding of LF and the MDA. Comparable observations have been made elsewhere [4, 26, 27], and reflect the need for the creation of awareness, through social mobilization and sensitization using evidence-based context-specific strategies and involvement of community leaders and other key stakeholders in deciding on the strategies and methods to be used to improve MDA activities towards LF control based on initial needs assessment $[5,11,28]$.

Intensive training and motivation for CDDs was also a particularly important factor that determines the success of the ongoing LF MDA in the study district, as shown elsewhere $[4,29]$.

The nature of contextual complexities and dynamics of populations in LF endemic areas may require that MDA activities are designed taking into consideration contextual factors based on WHO-recommended strategies [4, 5 , 30]. The use of social mobilization and sensitization materials and strategy should focus on the local context, needbased, social and culture structures $[4,31]$. This study also revealed that the involvement of community leaders, intensive training of CDDs and employing context-specific evidence-based social mobilization and sensitization strategies led to an improvement in the knowledge, attitude and practices relating to the disease, reduction in misconception regarding LF and MDA activities and willingness to ingest the LF medicine in the study area.

The fear of adverse drug reaction associated with the LF medication was an important factor that influenced the decision to take the MDA drugs and has been identified in several studies elsewhere [9, 32] and the study area [5]. In this study, the fear of adverse reactions improved after the implementation of QI intervention, indicating that the challenge of fear of adverse drug reaction in control of LF can be eradicated through the implementation of contextspecific educational strategies, building confidence in the populace, the outlining of the reasons for the occurrence of drug reactions, and what to do when they occur as indicated in this study. While misconception about the drug (enhances sexual performance) still exist in some areas, continuous appropriate education and advocacy may help overcome this challenge to avoid abuse of the drug.

This study has reinforced the importance of application of the RE-AIM framework for evaluation of public health intervention using a mixed-methods approach.

The increasing advocate for public health studies to apply both qualitative and mixed methods in health services delivery research has been demonstrated in other studies [33-37]. Guidance is scarce in the literature on how to apply qualitative methods in the RE-AIM framework [38]. Therefore, the inclusion of qualitative approaches in this study is a vital contribution to the full application of the RE-AIM model in assessing public health interventions [15,

Page $18 / 24$ 
39]. The combination of qualitative and quantitative methods helped to evaluate the CEQI intervention when very complex and unbiased quantitative data are not available or feasible [38].

Although the qualitative methods may not represent the entire study population, it added depth and meaning to facilitate understanding [38]. The methods in this study have also enriched the understanding and conclusion of the evaluation of the CEQI intervention. This approach can guard against the wrong assumption that an intervention or method did not work when it was an implementation failure [40,41]. Finally, the approaches used in this study has offered insight into how to guard against implementation failures in the future application of the CEQI intervention. Mixed methods can both enhance and advance the effective application of the RE-AIM [38].

\section{Limitations}

This study has some limitations. Social desirability bias could be a limitation to the study as some study participants might have withheld what they thought to be harmful practices during the implementation of the CEQI from the researchers. The duration of the intervention (one round of implementation) does not provide knowledge of the long-term effect and difficulties within the setting and with participants to be fully studied.

The CEQI intervention has been implemented for only one round of MDA. The intervention was limited to only one district in Northern Ghana; hence, limits the generalizability of the findings.

\section{Conclusion}

The findings of this study at the district and sub-district level, coupled with reach, effectiveness and adoption at the participant level, suggest that the CEQI intervention is feasible to implement in LF hotspot districts based on initial context-specific needs assessment.

Although there is an improvement in coverage, compliance, knowledge about the disease and MDA activities in the study area, the study further emphasized the need to improved context-specific social mobilization and sensitization focusing on the safety of medicines and the importance of MDA before and during the drug distribution exercises.

This study contributed to a growing body of knowledge about the design, implementation of QI interventions and application of RE-AIM framework in public health interventions. This has a far-reaching significance for the MDA exercise in LF hotspot districts and future implementation of the CEQI intervention and application of the RE-AIM framework.

The study provided an avenue to understanding the effect of implementing context-specific evidence-based QI intervention based on an initial needs assessment to improve the ongoing LF MDA in a hotspot district. This has a far-reaching significance for MDA implementation in all other LF hotspot districts towards the elimination of LF as a public health problem in Ghana.

\section{Declarations}

\section{Ethics approval and consent to participate}

Ethical approval numbers: M170219 and GHS-ERC: 04/02/2017 were obtained from the Human Research Ethics Committee (Medical) of the University of the Witwatersrand, Johannesburg, South Africa and the Ghana Health Service Ethics Review Committee respectively before the commencement of the study. Written informed consent was 
sought from all research participants. All study participants were adults aged > 18years. ). Permission was obtained from Neglected Tropical Diseases (NTDs) program of the Ghana Health Services and the District Health Administration of Bole.

\section{Consent for publication}

Not applicable.

\section{Competing interest}

The authors declare that they have no competing interests.

\section{Funding}

This study was funded by TDR, the Special Programme for Research and Training in Tropical Diseases, which is hosted at the World Health Organization and co-sponsored by UNICEF, UNDP, the World Bank and WHO. TDR grant number: WHO/TDR/RCS/B40299. The funders had no role in study design, data collection and analysis, decision to publish, or preparation of the manuscript.

\section{Availability of data and materials}

The dataset supporting the conclusions of this article is included in the article.

\section{Acknowledgements}

The authors are very grateful to all the study participants who provided useful insights and the support of the National Neglected Tropical Diseases Program in Accra, Ghana.

We also want to express our appreciation to the Ghana Health Service staff from the study district for their invaluable support and help.

This study is dedicated to Prof Margaret Gyapong for her mentorship, training and contribution towards the fight against Lymphatic Filariasis in Ghana.

\section{Author information}

Alfred Kwesi Manyeh, Tobias Chirwa, Ramaswamy Rohit, Frank Baiden, Latifat Ibisomi

\section{Affiliations}

Division of Epidemiology and Biostatistics, School of Public Health, University of the Witwatersrand, Parktown, Johannesburg, South Africa.

Alfred Kwesi Manyeh, Tobias Chirwa \& Latifat Ibisomi

University of Health and Allied Sciences, Ho, Volta Region, Ghana.

Alfred Kwesi Manyeh

Public Health Leadership Program, Gillings School of Global Public Health, University of North Carolina, 4107, McGavran-Greenberg Hall, Chapel Hill, NC, USA. 
Ramaswamy Rohit

Faculty of Infectious and Tropical Diseases, London School of Hygiene and Tropical Medicine, London WC1E 7HT, United Kingdom.

Frank Baiden

Nigerian Institute of Medical Research, Nigeria.

Latifat Ibisomi

\section{Contributions}

All authors have read and approved the manuscript. AKM: Participated in the conceptualization, the study design, data extraction, data analysis, data interpretation, and conducted the literature review. He wrote of the manuscript. RR, TC, FB and LI: Participated in refining the initial research idea and critically reviewed the drafts.

\section{Corresponding author}

Correspondence to Alfred Kwesi Manyeh

\section{References}

1. Zeldenryk LM, Gray M, Speare R, Gordon S, Melrose DW. The emerging story of disability associated with lymphatic filariasis: a critical review. PLoS Negl Trop Dis. 2011;5(12):e1366.

2. Molyneux D. Lymphatic filariasis (elephantiasis) elimination: a public health success and development opportunity. Filaria J. 2003;2:13.

3. WHO. Guideline - Alternative mass drug administration regimens to eliminate lymphatic filariasis. 2017d.

4. Biritwum N-K, Garshong B, Alomatu B, de Souza DK, Gyapong M, Kyelem D. Improving drug delivery strategies for lymphatic filariasis elimination in urban areas in Ghana. PLoS Negl Trop Dis. 2017;11(5):e0005619.

5. Manyeh AK, Ibisomi L, Baiden F, Chirwa T, Ramaswamy R. Using intervention mapping to design and implement quality improvement strategies towards elimination of lymphatic filariasis in Northern Ghana. PLoS Negl Trop Dis. 2019;13(3):e0007267.

6. Biritwum N-K, de Souza DK, Marfo B, Odoom S, Alomatu B, Asiedu O, et al. Fifteen years of programme implementation for the elimination of Lymphatic Filariasis in Ghana: Impact of MDA on immunoparasitological indicators. PLoS Negl Trop Dis. 2017;11(3):e0005280.

7. Babu BV, Mishra S. Mass drug administration under the programme to eliminate lymphatic filariasis in Orissa, India: a mixed-methods study to identify factors associated with compliance and non-compliance. Trans Roy Soc Trop Med Hyg. 2008;102:1207-13.

8. Cantey PT, Rao G, Rout J, Fox LM. Predictors of compliance with a mass drug administration programme for lymphatic filariasis in Orissa State, India 2008. Trop Med Int Health. 2010;15:224-31.

9. Krentel A, Fischer PU, Weil GJ. A Review of Factors That Influence Individual Compliance with Mass Drug Administration for Elimination of Lymphatic Filariasis. PLoS Negl Trop Dis. 2013;7(11):e2447.

10. Lemoine JF, Desormeaux AM, Monestime F, Fayette CR, Desir L, Direny AN, Baker M, et al. Controlling Neglected Tropical Diseases (NTDs) in Haiti: Implementation Strategies and Evidence of Their Success. PLoS Negl Trop Dis. 2016;10(10):e0004954. 
11. Njomo D, Amuyunzu-Nyamongo M, Mukoko D, Magambo J, Njenga S. Social mobilization and compliance with mass treatment for lymphatic filariasis elimination in Kenya. Afr J Health Sci. 2012;20:42-9.

12. Glasgow RE, McKay HG, Piette JD, Reynolds KD. The RE-AIM framework for evaluating interventions: what can it tell us about approaches to chronic illness management? Patient Educ Couns. 2001;44:119-27.

13. Finch CF, Gabbe BJ, Lloyd DG, Cook J, Young W, Nicholson M, Seward H, Donaldson A, Doyle TLA. Towards a national sports safety strategy: addressing facilitators and barriers towards safety guideline uptake. Inj Prev. 2011;17:1-10.

14. Dzewaltowski DA, Estabrooks PA, Glasgow RE. The future of physical activity behavior change research: what is needed to improve translation of research into health promotion practice? Exerc Sport Sci Rev. 2004;32:57-63.

15. Kessler RS, Purcell EP, Glasgow RE, Klesges LM, Benkeser RM, Peek CJ. What does it man to "employ" the REAIM model? Eval Health Prof. 2013;36:67-72.

16. Akers JD, Estabrooks PA, Davy BM. Translational research: bridging the gap between long-term weight loss maintenance research and practice. J Am Diet Assoc 2010(110):1511-1522.

17. Kahwati LC, Lance TX, Jones KR, Kinsinger LS. RE-AIM evaluation of the veterans health Administration's MOVE! weight management program. Transl Behav Med. 2011;1:551-60.

18. Dunton GF, Lagloire R, Robertson T. Using the RE-AIM framework to evaluate the statewide dissemination of a school-based physical activity and nutrition curriculum: "Exercise Your Options". Am J Health Promot. 2009;23:229-32.

19. Finch C. Implementing and Evaluating Interventions. In: In Injury research: theories, methods, and approaches. New York: Springer US; 2012.

20. Li F, Harmer P, Glasgow R, Mack KA, Sleet D, Fisher KJ, Kohn MA, Millet LM, Mead J, Xu J, et al. Translation of an effective Tai Chi intervention into a community-based falls-prevention program. Am J Public Health. 2008;98:1195-8.

21. Estabrooks PA, Bradshaw M, Dzewaltowski DA, Smith-Ray RL. Determining the impact of Walk Kansas: applying a team-building approach to community physical activity promotion. Ann Behav Med. 2008;36:1-12.

22. Gaglio B, Shoup J, Glasgow RE. The RE-AIM framework: a systematic review of use over time. Am J Public Health. 2013;103:e38-46.

23. Payne JM, France KE, Henley N, D'Antoine HA, Bartu AE, O'Leary CM, Elliott EJ, Bower C, Geelhoed E. RE-AIM evaluation of the alcohol and pregnancy project: educational resources to inform health professionals about prenatal alcohol exposure and fetal alcohol spectrum disorder. Eval Health Prof. 2011;34:57-80.

24. Vick L, Duffy SA, Ewing LA, Rugen K, Zak C. Implementation of an inpatient smoking cessation programme in a veterans affairs facility. J Clin Nurs. 2013;22:866-80.

25. Oliver M. An introduction to the evaluation of learning technology. Edu Technol Soc. 2000;3:20-30.

26. Nandha B, Sadanandane C, Jambulingam P, Das P. Delivery strategy of mass annual single dose DEC administration to eliminate lymphatic filariasis in the urban areas of Pondicherry, South India: 5 years of experience. Filaria J. 2007;6:7.

27. Yirga D, Deribe K, Woldemicheal K, Wendafrash M, Kassahun W. Factors associated with compliance with community directed treatment with ivermectin for onchocerciasis control in Southwestern Ethiopia. Parasites Vectors. 2010;3:3-48.

28. Mwakitalu ME, Malecela MN, Pedersen EM, Mosha FW, Simonsen PE. Urban lymphatic filariasis in the city of Tanga, Tanzania, after seven rounds of mass drug administration. Acta Trop. 2013;128:692-700. 
29. Njomo DW, Amuyunzu-Nyamongo M, Magambo JK, Ngure PK, Njenga SM. Factors associated with the motivation of community drug distributors in the Lymphatic Filariasis Elimination Programme in Kenya. South Afr J Epidemiol Infect. 2012;27:66-70.

30. Njomo DW, Mukoko DA, Nyamongo NK, Karanja J. Increasing Coverage in Mass Drug Administration for Lymphatic Filariasis Elimination in an Urban Setting: a Study of Malindi Town, Kenya. PLoS One. 2014;9:e83413.

31. Molyneux DH, Hopkins A, Bradley MH, Kelly-Hope LA. Multidimensional complexities of filariasis control in an era of large-scale mass drug administration programmes: a can of worms. Parasites Vectors. 2014;7:363.

32. Cantey PT, Rout J, Rao G, Williamson J, Fox LM. Increasing Compliance with Mass Drug Administration Programs for Lymphatic Filariasis in India through Education and Lymphedema Management Programs. PLoS Negl Trop Dis. 2010;4:e728.

33. Creswell JW, Klassen AC, Plano C, et al: Best practices for mixed methods research in the health sciences. In: Office of the Behavioral and Social Sciences Research. Edited by MD B. National Institutes of Health; 2011.

34. Curry LA, Krumholz HM, O'Cathain A, et al. Mixed methods in biomedical and health services research. Circ Cardiovasc Qual Outcomes. 2013;6(1):119-23.

35. Plano Clark VL. The adoption and practice of mixed methods: U.S. trends in federally funded health-related research. Qual Inq. 2010;16:428-40.

36. Miller WL, Crabtree BF, Harrison MI, et al. Integrating mixed methods in health services and delivery system research. Health Serv Res. 2013;48(6 Pt 2):2125-33.

37. Palinkas LA, Cooper BR. Mixed methods evaluation in dissemination and implementation science. New York: Oxford University Press; 2017.

38. Holtrop JS, Rabin AB, Glasgow RE. Qualitative approaches to use of the REAIM framework: rationale and methods. BMC Health Services Research. 2018;18:177.

39. Gaglio B, Shoup JA, Glasgow RE. The RE-AIM framework: a systematic review of use over time. Am J Public Health. 2013;103(6):e38-46.

40. Bellg AJ, Borrelli B, Resnick B, et al. Enhancing treatment fidelity in health behavior change studies: best practices and recommendations from the NIH behavior change consortium. Health Psychol. 2004;23(5):44351.

41. Jr Castro BM, Strycker FG. LA, et al: Cultural adaptations of behavioral health interventions: a progress report. J Consult Clin Psychol. 2013;81(2):196-205.

\section{Figures}




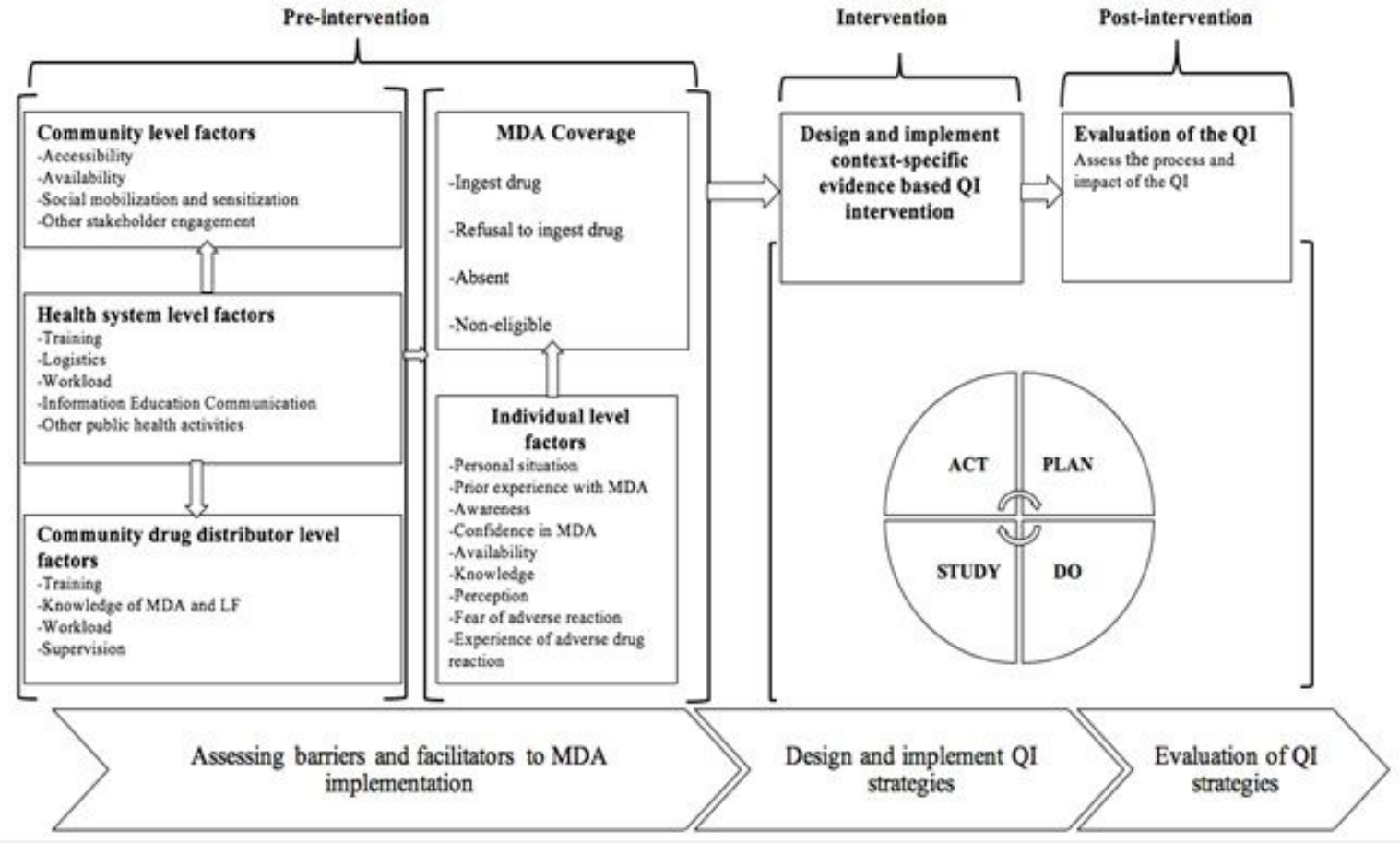

Figure 1

Conceptual framework showing the connection between the study phases.

\section{Supplementary Files}

This is a list of supplementary files associated with this preprint. Click to download.

- CoverLetter.docx 